\title{
Significance of Osteopontin Expression in Human Invasive Breast Tumour Stroma
}

\author{
Lígia R. Rodrigues ${ }^{*}, \mathrm{a}$, Nair Lopes ${ }^{\mathrm{b}}$, Bárbara Sousa ${ }^{\mathrm{b}}$, Daniella Vieira ${ }^{\mathrm{c}}$, Fernanda Milanezi ${ }^{\mathrm{b}}$, \\ Marie Paulsson ${ }^{\mathrm{d}}$, Helena Lindmark-Mänsson ${ }^{\mathrm{d}, \mathrm{e}}$, José A. Teixeira ${ }^{\mathrm{a}}$, Fernando Schmitt ${ }^{\mathrm{b}, \mathrm{f}}$
}

\author{
${ }^{a} I B B$ - Institute for Biotechnology and Bioengineering, Centre of Biological Engineering, Universidade do Minho, \\ 4710-057 Braga, Portugal \\ ${ }^{b}$ Instituto de Patologia e Imunologia Molecular - IPATIMUP, Universidade do Porto, Rua Dr. Roberto Frias, 4200-465 \\ Porto, Portugal \\ ${ }^{c}$ Departamento de Patologia/Universidade Federal de Santa Catarina, Serviço de Anatomia Patológica/Hospital Uni- \\ versitário da Universidade Federal de Santa Catarina, Florianópolis, Brasil \\ ${ }^{d}$ Department of Food Technology, Engineering and Nutrition, Lund University, P.O. Box 124, S-221 00, Lund, Sweden \\ ${ }^{e}$ Swedish Dairy Association, Scheelevägen 18, SE-223 63 Lund, Sweden \\ ${ }^{f}$ Faculdade de Medicina, Universidade do Porto, Al. Prof. Hernâni Monteiro 4200 - 319 Porto, Portugal
}

\begin{abstract}
Osteopontin has been reported to stimulate cell adhesion, migration and specific signalling functions. Its overexpression has been found in melanoma, breast, lung, colorectal, stomach and ovarian cancer. However, its overexpression and role in human breast cancer remains to be elucidated. In this study, invasive breast tumours from 129 patients were examined by immunohistochemistry in order to assess osteopontin association with several molecular tumour markers. Additionally, its relationship with proliferation and angiogenesis was determined. Ultimately, other tumour variables such as histological grade, tumour size and nodal status were also assessed. Results achieved showed that no statistical significant association exists between osteopontin expression and major clinicopathological parameters or angiogenesis, except for the number of lymph nodes involved. However, a correlation with some molecular markers was observed, namely with P-Cadherin, EGFR, cytokeratin 14 and vimentin. Additionally, higher proliferation rates were found for the tumours expressing osteopontin. Although several studies refer osteopontin as a potential breast cancer biomarker, it is still not clear if it can provide important diagnosis information, evaluate treatment effects or assess the potential for metastatic disease in patients.
\end{abstract}

Keywords: Osteopontin, tumour stroma, invasive breast cancer.

\section{INTRODUCTION}

Cancer biomarkers that allow the anticipation of the outlines of disease have been an emerging issue and there is a growing need for additional reliable molecular markers [1]. Osteopontin (OPN) is a phosphorylated glycoprotein found in all body fluids, extracellular matrix components, and proteinaceous matrix of mineralized tissues [2-4]. This protein was found to be overexpressed in tumours and serum of women with ovarian cancer, and was correlated with progression $[5,6]$. Furthermore, OPN has been detected in approximately $90 \%$ of primary breast carcinomas $[7,8]$, and recent studies demonstrated that its overexpression is also related with breast cancer evolution and metastasis [2, 9]; therefore there is a potential utility of OPN in monitoring disease status in breast cancer patients [10].

*Address correspondence to this author at the IBB - Institute for Biotechnology and Bioengineering, Centre of Biological Engineering, Universidade do Minho, 4710-057 Braga, Portugal; Tel: +351253604400;

Fax:+351253678986; E-mail: 1rmr@deb.uminho.pt
In human tissues, OPN has been found to be produced by epithelial cells of the gastrointestinal, urinary and reproductive tracts, the gallbladder, pancreas, lung bronchi, lactating breast, salivary glands and sweat ducts [11]. OPN was localized to the luminal surfaces in these sites, and also in human secretions including blood, milk and urine [10, 12]. Overall these findings suggested that OPN may have a protective role in interactions between epithelial surfaces and the external environment. Nevertheless, several studies have described a link between OPN and cancer in the past years [9, $10,13,14]$. Presently, it is fully accepted that OPN expressed by tumour cells alters their malignant properties, specifically by affecting their ability to grow, invade and metastasize. However, as OPN is known to be expressed in both normal and malignant tissues, an elucidation on its significance in human cancer is required.

The association of OPN with breast tumour progression was studied by Tuck and co-workers [15] using samples from a patient who had bilateral mammary carcinomas of similar histology and later developed metastatic recurrence. Their findings suggest that OPN, both in tumour cells and in 
plasma, may be a marker for tumour aggressiveness in breast cancer, and elevated levels in a primary tumour may predict the future development of metastasis. Furthermore, the same group studied the expression of OPN mRNA and protein in the tumours of 154 women with lymph node negative (LNN) breast cancer [16]. Results gathered in this study support the idea that OPN levels within tumour cells may be a useful predictor of patient outcome in breast cancer, and also that OPN may play a functional role in tumour progression and aggressiveness. A correlation between OPN expression and an increased invasiveness or metastatic potential has also been reported in other human tumours, such as melanoma, breast, lung, colorectal, stomach and ovarian cancer $[2,4,10$, 17].

Some studies have also reported an implicated OPN in angiogenesis, nevertheless many of the results remain circumstantial and further clarification on the details of this possible role is required $[18,19]$. The association of OPN to this process is a consequence of its ability to bind the $\alpha v \beta 3$ integrin, which in turn is a marker of angiogenesis and expressed by neovascular endothelial cells [19].

Recently, Finak and co-workers [20] reported the presence of OPN in the breast tumour stroma associated with a poor outcome cluster of genes linked to angiogenic, hypoxic and tumour-associated macrophage responses. Under normal physiological conditions, stroma serves as an important barrier to epithelial cell transformation; the interplay between epithelial cells and the microenvironment maintains epithelial polarity and modulates growth inhibition [21]. However, the stromal compartment undergoes changes in response to emerging epithelial lesions and can have a key role in cancer initiation and progression $[21,22]$. These changes may include the recruitment of immune endothelial cells providing growth and matrix remodelling factors, as well as a new blood supply promoting tumour growth and metastasis [2123].

Table 1. Antibodies Used in the Immunohistochemistry Study
The aim of the present study was to examine by immunohistochemistry (IHC) on tissue microarrays (TMAs), the OPN expression in invasive tumour stromas from 129 patients in order to assess its association with several molecular tumour markers (ER (estrogen receptor), HER2 (human epidermal receptor 2), CK5 (cytokeratin 5), CK14 (cytokeratin 14), CK8/18 (cytokeratin 8/18), p63, P-CD (P-cadherin), EGFR (epidermal growth factor receptor), PgR (progesterone), VIM (vimentin)). Additionally, the relationship of OPN with proliferation (Ki67) and angiogenesis (CD105 endoglin) was determined. Ultimately, other tumour variables such as histological grade, tumour size and nodal status were also assessed.

\section{MATERIALS AND METHODOLOGY}

\section{Patients' Selection}

One hundred and twenty nine tumour samples were obtained from patients treated at the Federal University of Santa Catarina, Florianopolis-SC, Brazil and kindly given to us for this work. Of these, 22 tumours presented clinical features of familial breast cancer according to the Breast Cancer Linkage Consortium [24, 25], 96 tumours were from patients without any clinical familial feature (sporadic) and 11 tumours had no clinical data available to determine if they have clinical features of familial breast cancer.

\section{Tissue Microarray Construction}

Representative areas of the invasive breast carcinomas were carefully selected on hematoxylin and eosin (H \& E) stained sections and marked on the correspondent individual paraffin blocks. Two tissue cores ( $2 \mathrm{~mm}$ in diameter) were obtained from each selected specimen and precisely deposited into a recipient paraffin block using TMA workstation (TMA builder ab1802, Abcam, Cambridge, UK). Eighteen TMA blocks were constructed, each containing 24 tissue cores, arranged in a $4 \times 6$ sector. In each TMA block, nonneoplastic breast and testicular tissue cores were also included as controls and TMA guide, respectively. After construction, 2

\begin{tabular}{|c|c|c|c|c|c|}
\hline Molecular Marker & Antibody & Origin & Clone & Dilution & Antigenic Retrieval (min) \\
\hline \hline ER & Rmab & Neomarkers, USA & SP1 & $1: 150$ & 30 \\
\hline HER2 & Rmab & Neomarkers, USA & SP3 & $1: 80$ & 30 \\
\hline CK5 & Mmab & Neomarkers, USA & XM26 & $1: 50$ & 30 \\
\hline P63 & Mmab & Neomarkers, USA & 4 A4 & $1: 150$ & 30 \\
\hline P-CD & Mmab & BD Transduction, KY, USA & 56 & $1: 50$ & 30 \\
\hline EGFR & Mmab & Zymed, USA & 31 G7 & $1: 100$ & 30 \\
\hline CK14 & Mmab & Novocastra, UK & LL002 & $1: 400$ & 30 \\
\hline CK8/18 & Mmab & Zymed, USA & UCD/PR-10.11 & $1: 50$ & 40 \\
\hline PgR & Rmab & Neomarkers, USA & SP2 & $1: 300$ & 30 \\
\hline VIM & Mmab & DakoCytomation & V9 & $1: 150$ & 30 \\
\hline Ki67 & Rmab & Neomarkers, USA & SP6 & $1: 300$ & 30 \\
\hline OPN & Mmab & Santa Cruz, USA & AKm2A1 & $1: 500$ & 30 \\
\hline CD105 & Mmab & Novocastra, UK & 4G11 & $1: 50$ & 30 \\
\hline
\end{tabular}


$\mu \mathrm{m}$ tissue sections were cut and adhered to Superfrost Plus glass slides. An $\mathrm{H} \& \mathrm{E}-$ stained section from each block was reviewed to confirm the presence of morphological representative areas of the initially identified lesions. All the markers were assayed in TMAs, except for CD105 (endoglin) that was assayed using whole tissue sections of each case.

\section{Immunohistochemistry}

Immunohistochemical staining for ER, HER2, CK8/18, VIM, CK5, p63, OPN, LF and CD105 was performed using the streptavidin-biotin-peroxidase technique (LabVision Corporation, Fremont, CA, USA) in each set of 18 glass slides comprising the TMAs, whereas P-CD, CK14, EGFR, Ki67 and PgR used the HRP labelled polymer (DakoCytomation, Carpinteria, CA, USA).

Antigen unmasking for p63, ER, HER2, OPN, VIM, PgR, Ki67 and CD105 was carried out using a dilution of 1:100 from a commercially available solution of citrate buffer, $\mathrm{pH}=6.0$ (Vector Laboratories, Burlingame, CA, USA) at $98^{\circ} \mathrm{C}$, whereas a dilution of 1:10 from tris-ethylenedi-aminetetraacetic (EDTA) solution with $\mathrm{pH}=9.0$ (DakoCytomation) was used for CK5, P$\mathrm{CD}$ and CK14.

Epitope retrieval for EGFR was performed by proteolytic enzyme digestion (pepsin A, 4 g/l; Sigma-Aldrich, Germany) at $37^{\circ} \mathrm{C}$, and for $\mathrm{CK} 8 / 18$ a solution of PT Module Buffer (LabVision) was used.

The antigen retrieval times, antibodies, dilutions and suppliers are listed in Table 1. After washes in a phosphate buffer solution (PBS), endogenous peroxidase activity was blocked by incubation of the slides in a 3\% hydrogen peroxide (Panreac, Spain) in methanol (Sigma-Aldrich). The slides were incubated with a blocking serum (LabVision) for $15 \mathrm{~min}$ and then incubated with the specific antibody.

Primary antibody incubation was performed for $30 \mathrm{~min}$ utes at room temperature (ER, HER2, PgR, CK8/18 and VIM), for $1 \mathrm{~h}$ at room temperature (P-CD, p63, CK5, EGFR, $\mathrm{CK} 14, \mathrm{Ki} 67$ and $\mathrm{OPN}$ ) or overnight at $4^{\circ} \mathrm{C}$ (CD105). After washes, the slides were incubated with biotinylated secondary antibody, followed by streptavidin-conjugated peroxidase (LabVision). Diaminobenzidine (DAB) was used as a chromogen (DakoCytomation).

For P-CD, CK14, EGFR, Ki67 and PgR staining, the secondary antibody was associated with HRP labelled polymer (DakoCytomation) and immediately revealed with DAB. Tissues were then counterstained with Mayer's hematoxylin, dehydrated and coverslipped using a permanent mounting solution (Zymed, San Francisco, CA, USA).

Positive controls were included in each run in order to guarantee the reliability of the assays. Nonneoplastic breast tissue cores, as well as normal breast surrounding the neoplastic cells, were considered internal controls for most of the antibodies tested: p63, CK5, CK14, P-CD, EGFR (myoepithelial cells); ER $\alpha, \mathrm{PgR}, \mathrm{CK} 8 / 18$ (epithelial cells); VIM (stromal cells). The evaluation of immunohistochemistry results was done by two pathologists (F. Schmitt and F. Milanezi), as follows: P-CD was considered positive whenever more than $10 \%$ of the neoplastic cells showed membrane staining, usually associated to cytoplasmic staining [26]; similarly, we adopted the same cutoff value for nuclear $\mathrm{ER} \alpha$ and $\mathrm{PgR}$ reactivity.
CK5, CK14, OPN and VIM were considered positive whenever any cytoplasmic staining was observed in the neoplastic cells. OPN expression was evaluated also in the stroma component of the tumour [15, 16, 20, 27-31]. p63 was considered positive whenever nuclear staining was seen, and CK8/18 was considered positive whenever cytoplasmic and/or membrane staining was observed. HER2 expression was evaluated according to the DakoCytomation HercepTest scoring system: 0 - no staining or membrane staining in fewer than $10 \%$ of tumour cells; $1+$ - faint, barely perceptible membrane staining in more than $10 \%$ of tumour cells, the cells are stained only in part of the membrane; $2+$ - weak to moderate complete membrane staining observed in more than $10 \%$ of tumour cells; and $3+$ - strong, complete membrane staining in more than $10 \%$ of tumour cells. Cases were considered positive (overexpression) for HER2 when the immunostaining was classified as $3+$. EGFR staining was also classified according to the HercepTest scoring system, but breast carcinomas were considered positive whenever the immunostaining was $2+$ or $3+$. Three categories were defined for Ki67: $<10 \%, 10-20 \%$ and $>20 \%$ of stained nuclei. For CD105 evaluation, tumour microvessel density was determined by the average number of new vessels, counted with an amplification of $200 \mathrm{X}$, in 3 different hotspots.

Finally, according to several authors $[32,33]$ we classified each tumour in a practical way based on its ER and HER2 expression.

\section{Statistical Analysis}

The $\chi^{2}$ contingency test was used for categorical variables to determine differences between the phenotypes. A $p$ value of less than 0.05 was considered to reflect a significant association. The angiogenesis data were compared using the non parametric Mann-Whitney test at a confidence level of $95 \%$. Data processing and statistical analysis were performed using Microsoft Office Excel 2007 (Microsoft Corp, Redmond, WA) and SPSS 16.0 software (SPSS Inc., Chicago, Illinois, USA).

\section{RESULTS}

\section{Immunohistochemistry Profiles in Breast Tumours}

We performed IHC for ER, HER2, EGFR, PgR, CK5, P63, P-CD, CK14, CK8/18, VIM, Ki67 and OPN. The CD105 assay was performed using whole tissue sections. The results obtained are gathered in Table 2 and Fig. (1). In our series we observed that $61.2 \%$ of breast carcinomas were ER-positive, and $22.7 \%$ were HER2-positive. Less than $34.4 \%$ of the tumours analyzed presented expression of a basal marker (PCD, p63, CK14 and CK5). Table 3 summarizes the clustering of a total of 129 cases immunohistochemically interpretable to allow sample characterization into one of five groups (Luminal A, luminal B, basal, HER2 overexpressed or unclassified) as described elsewhere [32]. Based on this classification, we observed that basal-like comprised $16.3 \%$ of all tumours, whereas luminal A and B comprised 54.3\% and 5.4\%, respectively. HER2-overexpressing tumours represented $17.1 \%$ of the series, and null phenotype/unclassified, 7.0\% (Table 3). As expected the protein expression profiles clearly differed in luminal $\mathrm{A}$, luminal $\mathrm{B}$, basal, and HER2-overexpressing tumours concerning P-CD, CK5, EGFR, CK14, CK8/18, PgR, VIM, Ki67, and CD105 (data not shown). Furthermore, we 
Table 2. Results of Immunohistochemistry Staining on Tissue Microarrays

\begin{tabular}{|c|c|c|c|}
\hline $\begin{array}{c}\text { Molecular } \\
\text { Marker }\end{array}$ & $\begin{array}{c}\text { Interpretable } \\
\text { Cores (n) }\end{array}$ & $\begin{array}{c}\text { Positive } \\
\text { Staining (\%) }\end{array}$ & $\begin{array}{c}\text { Negative } \\
\text { Staining (\%) }\end{array}$ \\
\hline \hline ER & 129 & 61.2 & 38.8 \\
\hline HER2 & 128 & 22.7 & 77.3 \\
\hline CK5 & 129 & 25.6 & 74.4 \\
\hline P63 & 129 & 6.2 & 93.8 \\
\hline P-CD & 128 & 34.4 & 65.6 \\
\hline EGFR & 128 & 2.3 & 97.7 \\
\hline CK14 & 128 & 6.3 & 93.8 \\
\hline CK8/18 & 127 & 100.0 & 0.0 \\
\hline PgR & 129 & 35.7 & 64.3 \\
\hline Vimentin & 129 & 13.2 & 86.8 \\
\hline OPN & 129 & 43.4 & 56.6 \\
\hline
\end{tabular}

Table 3. Frequencies of Immunohistochemistry Defined Subtypes of Breast Carcinomas in 129 Invasive $\mathrm{Tu}-$ mours for the Tested Markers Using Tissue Microarrays

\begin{tabular}{|c|c|c|c|}
\hline Subtype & ER & HER2 & Frequency $\left[\mathbf{n}^{*}, \mathbf{( \% )}\right]$ \\
\hline \hline Luminal A & + & - & $70(54.3)$ \\
\hline Luminal B & + & + & $7(5.4)$ \\
\hline HER2-overexpressed & - & + & $22(17.1)$ \\
\hline Basal & - & - & $21(16.3)$ \\
\hline Unclassified** & - & - & $9(7.0)$ \\
\hline
\end{tabular}

* Interpretable cores.

** Basal markers, such as P-CD, p63, CK14 and CK5, are also negative.

examined the relationship between OPN expression in tumour stroma and the other molecular markers tested, as well as with other tumour variables such as size, nodal status and histological grade. From a total of 129 cases immunohistochemically interpretable, we found that $43.4 \%$ of the cases showed a positive staining for OPN in the tumour stroma (Table 2). Among the OPN positive cases, the distribution of cancer subtypes found was 50.0\% Luminal A, 5.4\% Luminal B, 23.2\% Basal and 17.9\% HER2-overexpressing tumours $(\mathrm{p}=0.304)$ (Table 4). Moreover, regarding cancer subtype, it can be seen from Table 4 that cases negative for OPN showed higher percentages of Luminal A (57.5\%) tumours as compared with the positive ones. Significant statistically differences between the two groups (OPN positive and OPN negative) were observed for few of the studied molecular markers, such as P-CD ( $\mathrm{p}=0.032)$, EGFR ( $\mathrm{p}=0.077)$, CK14 $(p=0.066)$ and VIM $(p=0.069)$. OPN positive tumours presented mainly histological grade I and II (30.4\% and $43.5 \%$, respectively) and demonstrated a higher frequency of $\mathrm{P}-\mathrm{CD}$ and VIM expression (44.6\% and $19.6 \%$, respectively) as compared to OPN negative tumours (no statistical significance was although observed, $\mathrm{p}=0.941$ ). On the other hand, cases negative for OPN showed mainly histological grade II (46.5\%) and higher frequency of cases ER-positive, PgRpositive and P-CD-negative $(64.4 \%, 41.1 \%$ and $73.6 \%$,
Table 4. Immunohistochemistry Profiles of OPN Staining in Tumour Stroma

\begin{tabular}{|c|c|c|c|c|}
\hline & & $\begin{array}{c}\text { OPN + } \\
{\left[\mathbf{n}^{*},(\%)\right]}\end{array}$ & $\begin{array}{c}\text { OPN - } \\
{\left[n^{*},(\%)\right]}\end{array}$ & $\mathbf{p}$ \\
\hline \multirow{5}{*}{$\begin{array}{l}\text { Tumour } \\
\text { subtype }\end{array}$} & Luminal A & $28(50.0)$ & $42(57.5)$ & \multirow{5}{*}{0.304} \\
\hline & Luminal B & $3(5.4)$ & $4(5.5)$ & \\
\hline & Basal & $13(23.2)$ & $8(11.0)$ & \\
\hline & $\begin{array}{c}\text { HER2 } \\
\text { overexpressed }\end{array}$ & $10(17.9)$ & $12(16.4)$ & \\
\hline & Unclassified & $2(3.6)$ & $7(9.6)$ & \\
\hline \multirow{3}{*}{$\begin{array}{c}\text { Histological } \\
\text { grade }\end{array}$} & Grade I & $14(30.4)$ & $22(31.0)$ & \multirow{3}{*}{0.941} \\
\hline & Grade II & $20(43.5)$ & $33(46.5)$ & \\
\hline & Grade III & $12(26.1)$ & $16(22.5)$ & \\
\hline \multirow{20}{*}{$\begin{array}{c}\text { Molecular } \\
\text { markers }\end{array}$} & $\mathrm{ER}+$ & $32(57.1)$ & $47(64.4)$ & \multirow{2}{*}{0.513} \\
\hline & ER - & $24(42.9)$ & $26(35.6)$ & \\
\hline & HER2 + & $13(23.6)$ & $16(22.2)$ & \multirow{2}{*}{1.000} \\
\hline & HER2 - & $42(76.4)$ & $56(77.8)$ & \\
\hline & CK5 + & $15(26.8)$ & $18(24.7)$ & \multirow{2}{*}{1.000} \\
\hline & CK5 - & $41(73.2)$ & $55(75.3)$ & \\
\hline & P63+ & $5(8.9)$ & $3(4.1)$ & \multirow{2}{*}{0.293} \\
\hline & P63 - & $51(91.1)$ & $70(95.9)$ & \\
\hline & $\mathrm{p}-\mathrm{CD}+$ & 25 (44.6) & $19(26.4)$ & \multirow{2}{*}{0.032} \\
\hline & p- CD - & $31(55.4)$ & $53(73.6)$ & \\
\hline & EGFR + & $3(5.5)$ & $0(0.0)$ & \multirow{2}{*}{0.077} \\
\hline & EGFR - & $52(94.5)$ & $73(100.0)$ & \\
\hline & CK14 + & $6(10.7)$ & $2(2.8)$ & \multirow{2}{*}{0.066} \\
\hline & CK14 - & $50(89.3)$ & $70(97.2)$ & \\
\hline & $\mathrm{CK} 8 / 18+$ & $56(100.0)$ & $71(100.0)$ & \multirow{2}{*}{1,000} \\
\hline & CK8/18 - & $0(0)$ & $0(0)$ & \\
\hline & $\operatorname{PgR}+$ & $16(28.6)$ & $30(41.1)$ & \multirow{2}{*}{0.194} \\
\hline & PgR - & $40(71.4)$ & 43 (58.9) & \\
\hline & VIM + & $11(19.6)$ & $6(8.2)$ & \\
\hline & VIM - & $45(80.4)$ & $67(91.8)$ & \\
\hline \multirow{3}{*}{$\begin{array}{c}\text { Proliferation } \\
\text { rates Ki67 }\end{array}$} & $<10 \%$ & $19(34.5)$ & $49(67.1)$ & \multirow{3}{*}{0.001} \\
\hline & $10-20 \%$ & $5(9.1)$ & $6(8.2)$ & \\
\hline & $>20 \%$ & $31(56.4)$ & $18(24.7)$ & \\
\hline \multirow{3}{*}{ Tumour size } & $\mathrm{T} 1(<2 \mathrm{~cm})$ & $18(33.3)$ & $24(35.3)$ & \multirow{3}{*}{0.572} \\
\hline & $\mathrm{T} 2(2-5 \mathrm{~cm})$ & $29(53.7)$ & $31(45.6)$ & \\
\hline & $\mathrm{T} 3(>5 \mathrm{~cm})$ & $7(13.0)$ & $13(19.1)$ & \\
\hline \multirow{2}{*}{$\begin{array}{l}\text { Lymph nodes } \\
\text { metastases }\end{array}$} & Yes (86 cases) & $33(62.3)$ & $53(75.7)$ & \multirow{2}{*}{0.117} \\
\hline & No (37 cases) & $20(37.7)$ & $17(24.3)$ & \\
\hline \multirow{3}{*}{$\begin{array}{l}\text { Number of } \\
\text { lymph nodes } \\
\text { involved }\end{array}$} & 0 & $14(42.4)$ & $11(20.8)$ & \multirow{3}{*}{0.107} \\
\hline & $1-3$ & $9(27.3)$ & $19(35.8)$ & \\
\hline & $>3$ & $10(30.3)$ & $23(43.4)$ & \\
\hline
\end{tabular}

* Interpretable cores. 
a1

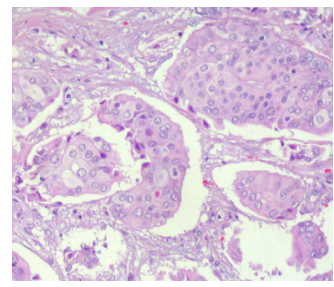

c1

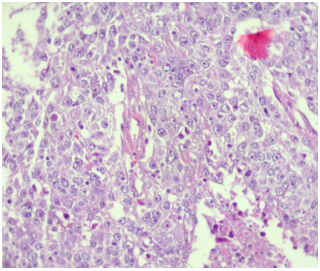

e1

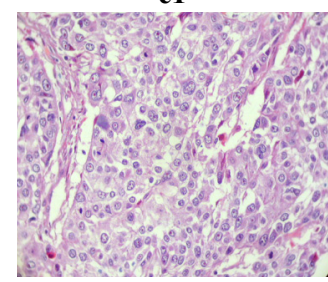

g1

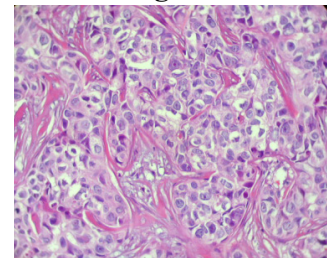

i1

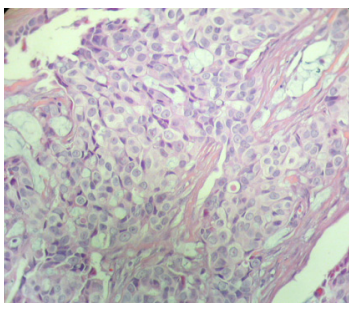

11

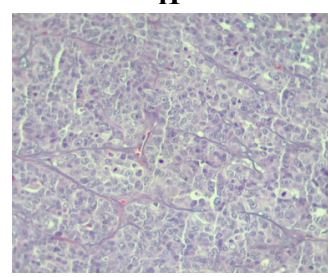

n1

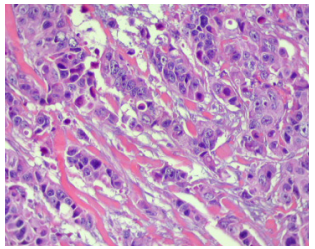

a2

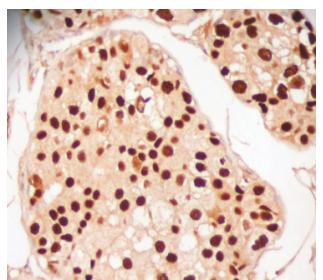

c2

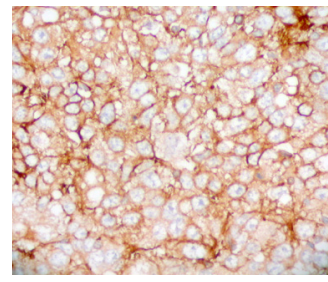

e2

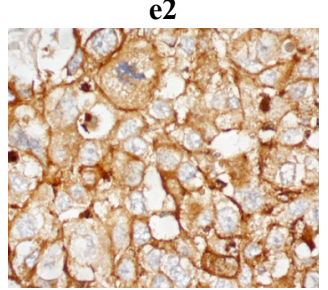

g2

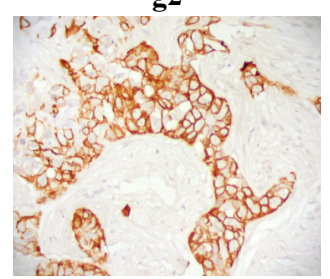

i2

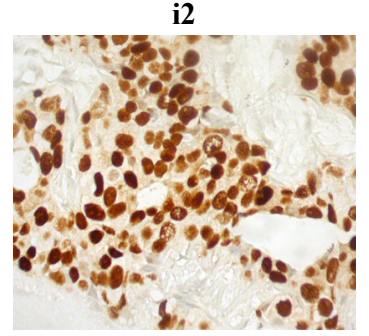

12

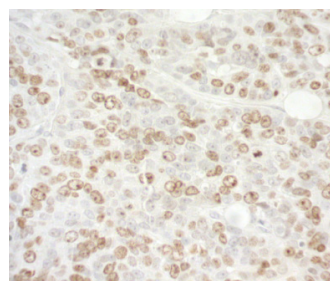

n2

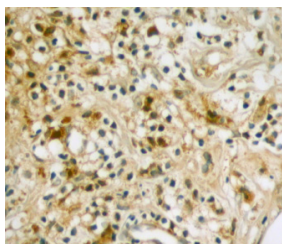

b1

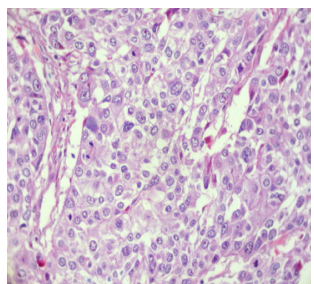

d1

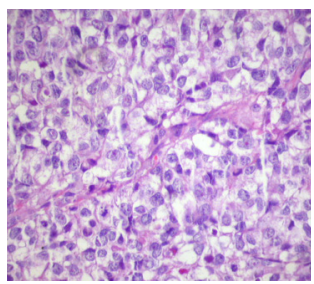

f1

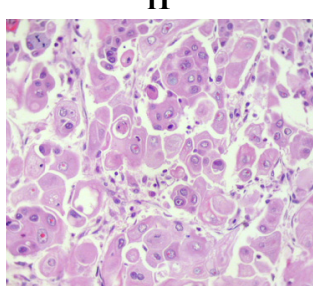

h1

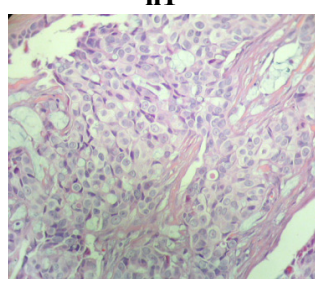

j1

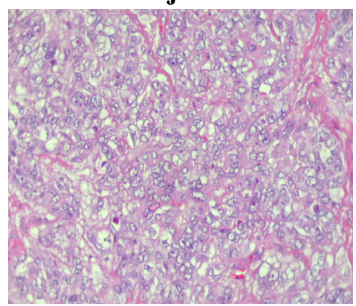

m1

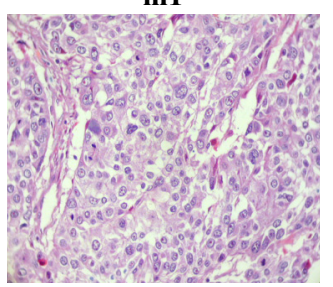

b2

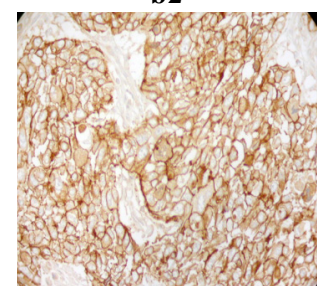

d2

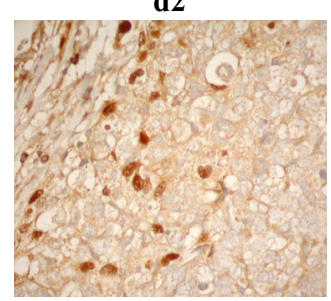

f2

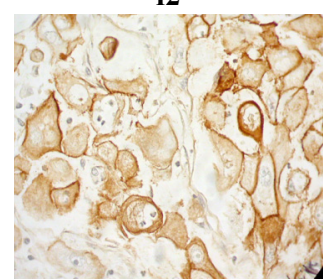

h2

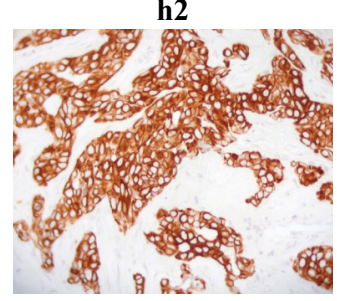

j2

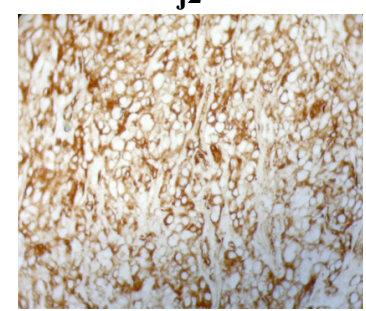

$\mathbf{m} 2$

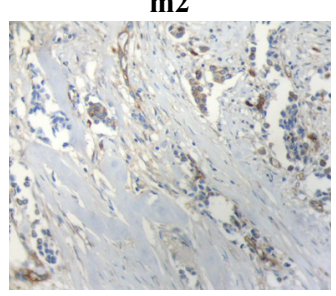

Fig. (1). Expression of proteins and H\&E staining of the core represented in each marker studied by IHC on TMAs. All TMA cores represent neoplastic tissue with a strong staining pattern. Except for cases $\mathbf{d 2}, \mathbf{e 2}, \mathbf{f} \mathbf{2}, \mathbf{i} \mathbf{2}$ and $\mathbf{1 2}$ where it was used an original magnification of X630, for all the others it was used X400: (a1, a2) - (H\&E, ER staining); (b1, b2) - (H\&E, HER2 staining); (c1, c2) - (H\&E, CK5 staining); (d1, d2) - (H\&E, p63 staining); (e1, e2) - (H\&E, P-CD staining); (f1, f2) - (H\&E, EGFR staining); (g1, g2) - (H\&E, CK14 staining); (h1, h2) (H\&E, CK8/18 staining); (i1, i2) - (H\&E, PgR staining); (j1, j2) - (H\&E, VIM staining); (11, 12) - (H\&E, Ki67 staining); (m1, m2) - (H\&E, CD105 staining); (n1, n2) - (H\&E, OPN stroma staining). 
respectively). A low expression of basal markers was observed for both groups (OPN positive and OPN negative). Microvessel density is regarded as a surrogate marker for angiogenesis and has been used for tumour prognosis. In this study, microvessel density was identified immunohistochemically using a monoclonal antibody against CD105 (endoglin) in invasive breast cancer tissue sections. The expression of CD105 in the microvessels within both groups, OPN-positive (mean $26 \pm 9$ microvessels $/ \mathrm{mm}^{2}$; range 9-47) and OPNnegative (mean $24 \pm 10$ microvessels $/ \mathrm{mm}^{2}$; range 9-72), was similar and no statistical significant difference was observed $(\mathrm{p}=0.298)$.

Regarding the Ki67 proliferation indices (indicator of prognosis in breast cancer), a strong statistical difference $(\mathrm{p}=0.001)$ could be observed between OPN- positive and negative groups. Higher Ki67 proliferation indices (> 20\%) were detected for the OPN-positive group (56.4\%) (Table 4).

Regarding tumour size (Table 4), we observed that OPNpositive cases showed higher frequencies of tumours between 2 and $5 \mathrm{~cm}(53.7 \%)$, whereas cases OPN-negative showed higher frequencies of T1 (smaller than $2 \mathrm{~cm})(35.3 \%)$ $(p=0.572)$. Additionally, we found that the cases OPNnegative showed a higher number of lymph nodes involved $(>3)$ as compared to the cases OPN-positive (Table 4) $(\mathrm{p}=0.107)$.

\section{DISCUSSION}

The purpose of this work has been to establish, using immunohistochemical techniques, the level of expression of the glycoprotein OPN in the stroma of human invasive breast carcinomas and its clinical significance. We have found that $43.4 \%$ of the carcinomas are stained positively for OPN by the mouse monoclonal antibody to human OPN (mAB clone Akm2A1), which is slightly below the overall staining levels previously reported with other antibodies, namely with a monoclonal antibody mAB 53 prepared against the recombinant GST-human OPN fusion protein, or with a rabbit polyclonal antibody to human OPN (70-80\%). The mAB Akm2A1 antibody used in this study as proven to be very specific for OPN, especially for endometrial carcinomas $[7,15,16,25,28$, $34,35]$. As referred previously and in agreement with other reports $[9,10,16,36]$, the staining in specimens is not restricted to carcinoma cells, because variable, often reduced levels are detected in normal parenchymal breast tissue and in some reactive fibroblast-like cells, macrophages, lymphocytes and blood vessels [37, 38]. Furthermore, OPN was recently found in the breast cancer stroma [20] associated with a poor outcome cluster of genes linked to angiogenic, hypoxic and tumour-associated macrophage responses. Contrary to previous published results [16, 29, 39], in this study no significant association could be observed between OPN expression and tumour variables such as nodal status $(p=0.107)$ and tumour size $(p=0.572)$. Nevertheless, these results are in accordance with those published by Kim and co-workers [28] that also failed to find an association of immunohistochemical staining for OPN and any clinicopathological parameters in 253 cases of breast cancer. In their study, $87 \%$ of the patients exhibited OPN-positive carcinomas, which is considerably higher than other reports. This higher proportion was found to be a consequence of using a polyclonal antibody to human OPN that recognizes an extra $\mathrm{Mr} 45,000$ polypeptide in extracts of breast cancers, and therefore this number of positive cases was overestimated. Furthermore, Ribeiro-Silva and co-workers [40] also studied OPN expression in invasive breast cancers and couldn't correlate it with several markers and clinicopathological features, such as grading and tumour size. In addition, also no correlation between OPN expression and basallike phenotype was found. It is important to notice that although several studies have been published recently on the involvement of OPN in breast cancer (and other types of cancer) $[2,15,16,20,28,29]$, it is not straightforward to compare the results obtained by different researchers. Some of these studies were performed using cell lines [2, 37], plasma [2] or paraffin blocks of tumours [16, 28, 29, 37]. Moreover, these studies focus on parameters such as disease free and patient survival, that were not included in our study. In addition, the most commonly reported markers are p53, ER and PR. Therefore, some of the molecular markers used in our work have never been studied together with OPN.

The fact that there is no significant correlation between the presence of OPN and major pathological tumour variables associated with poor patient prognosis as lymph node metastasis and tumour size, may reflect the characteristics of the tumours in this group of patients $(54.3 \%$ luminal-type A and $16.3 \%$ basal-type), as well as the size of the sample. Patients with luminal-type A tumours have the most favourable prognosis, whereas patients with basal-type tumours have worst prognosis [41]. Our results are in accordance with the work described by Rudland and co-workers [29], as they state that the association of OPN with worse prognosis appears to be independent of nodal status and other established clinical prognostic indicators. In our study, a minority (16.4\%) of the tumours are classified as T3; this is a small fraction in comparison with other groups of patients [42]. Moreover, nodal status has been undertaken on only $62.3 \%$ of the tumours. These smaller numbers may be responsible for the less meaningful associations.

Additionally, several molecular markers were tested for association with immunohistochemical staining for OPN in human invasive breast carcinomas, however only P-CD, EGFR, CK14 and VIM, showed statistical significance.

As in other types of carcinomas, transformation of the normal breast epithelium into an invasive malignancy is the result of multiple steps. These steps consist of transformation of normal to an atypical hyperplastic epithelium with a subsequent high risk of progression to intraductal carcinoma, followed in some cases by invasion into the stroma [43]. A basic feature of normal breast histology is the maintenance of specific adhesive relationships between epithelial cells, between epithelial and myoepithelial cells, and between cells and the extracellular matrix. Disruption or deregulation of these adhesive relationships causes a loss of ductal and lobular architecture and accompanies neoplastic transformation. Furthermore, progression to malignant phenotypes involves local invasion and metastasis, two processes in which cell-cell and cellextracellular matrix adhesions are altered. The mechanism of OPN overexpression and its role in human breast cancer is not clear. Although it is generally accepted that OPN occurs in the carcinoma cells themselves, the relative proportion sequestered from host cells such as activated macrophages and/or lymphocytes, and that is produced in situ has varied considerably $[27,36]$, but at least a sizeable proportion is now be- 
lieved to arise from overexpression of OPN mRNA in the carcinoma cells themselves $[7,16,34,37]$. OPN interacts with a variety of cell surface receptors, including several integrins and CD44, stimulating cell adhesion, migration, and specific signalling functions $[9,10,29,38,44,45]$. Additionally, OPN has been reported to play a role in tumour invasion and metastasis, where adhesive interactions between tumour cells and extracellular matrix are critical [8].

VIM is the intermediate filament protein usually restricted to mesenchymally derived tissue and which has been strongly correlated with basement membrane invasiveness in vitro by a variety of tumour cell lines [46]. VIM-positive cells, as a group, are significantly more invasive than their more epithelial counterparts, and expression of VIM in epithelial tumours is thought to arise by a process resembling the epithelial to mesenchymal transition (EMT). The EMT, known to occur transiently when epithelial cells need to adopt a migratory and possibly invasive state during embryogenesis, organ development, and wound healing, has been shown to be regulated by both growth factors and extracellular matrix (ECM) components [46]. Although only of borderline significance, our results showed a positive correlation between OPN and VIM expression which is in accordance with the previous reports [46]. Moreover, it has been reported that VIM is positively correlated with EGFR and Ki67 [47], and in our study we also found a positive correlation between OPN and these markers.

A co-expression of P-CD and OPN was found in this study; however these results are distinct from the ones obtained by Cheng and co-workers [48]. These researchers found that a dominant negative E-cadherin implied a transiently increase of OPN expression, but a decreased cell-cell adhesion associated with altered bone matrix protein expression and a decreased matrix mineralization. P-CD is restricted to the basal or lower layers of stratified epithelia, suggesting that in addition to maintaining cellular adhesion, P-CD may have other functions in differentiation and cell growth, as well as OPN $[49,50]$. Although both P-CD and OPN have been reported as having an adhesive function, their role may be different and not necessarily correlated, thus, further work is necessary in order to elucidate a possible relation between these proteins.

Additionally, some researchers found that a ligation of integrins by OPN leads to activation of EGFR receptor [51, 52] via src-dependent transactivation, with resulting activation of downstream signalling pathways such as P13K, RasMAPK, PLC and PKC, in turn activating AP-1 dependent uPA expression [53]. In our study, a significant association was found between OPN and EGFR.

Finally, OPN has been implied in tumour cell proliferation and angiogenesis $[3,18,37,54]$. A strong tendency for higher proliferation rates was achieved for OPN-positive cases, which is in accordance with the literature. This tendency is probably associated with the activation of different components of the local adhesion complex that could in turn activate a number of different signal transduction pathways affecting cellular properties such as proliferation $[9,10]$. Some studies have reported an implicated OPN in angiogenesis, however, many of the results remain circumstantial and further clarification on the details of this possible role are required. The association of OPN with this process is a consequence of its ability to bind $\alpha v \beta 3$ integrin, which in turn, is a marker of angiogene- sis and is expressed by neovascular endothelial cells $[3,10$, $37,54]$. Nevertheless, in this study no significant difference could be observed between OPN-positive and -negative cases regarding angiogenesis.

Endoglin has been reported to be upregulated in proliferating endothelial cells and to be strongly expressed in the neovasculature of a wide range of solid tumours [55]. In non malignant adult tissue vessels, including pre-neoplastic lesions, endoglin expression is weaker than in tumour vessels and often restricted to capillaries [55]. According to Balza and co-workers [56], although endoglin is upregulated in tumour vasculature, its expression is not restricted to tumour tissues, and their findings shown a widespread distribution of the antigen in vessels of normal adult tissues. Therefore, further detailed analyses are needed in view of endoglin-specific antibody applications in tumour diagnosis.

\section{CONCLUSION}

In sum, it remains to be determined how widespread the association between OPN and patient survival will prove to be, not only in breast but in other metastatic carcinomas. Thus far pilot studies on a small group of lymph node-negative breast cancer [16] and gastric cancer [17] patients have shown a positive association with patient demise and disease progression, respectively, whereas in ovarian cancers a surprising association with low malignant tumours has been reported [57]. With this work, we showed, in one group of invasive human breast cancer cases, that no statistical significant association exists between OPN expression, major clinicopathological parameters and some of the commonly used molecular markers. Also, no correlation was found between OPN expression and angiogenesis as discussed above. Nevertheless, a strong tendency for higher proliferation rates was observed for individuals classified as OPN-positive. Therefore, although many studies have been recently published on OPN potential as a breast cancer biomarker, it is still not clear if it can provide important diagnosis information, evaluate treatment effects or assess the potential for metastatic disease in patients.

\section{ACKNOWLEDGEMENTS}

The F.C.T. (Fundação para a Ciência e a Tecnologia - Portugal) provided financial support for LR through a post doctoral research grant $\mathrm{SFRH} / \mathrm{BPD} / 26064 / 2005$ and to $\mathrm{NL}$ through a research grant POCTI/CBO/45157/2002.

\section{REFERENCES}

[1] Lacroix M, Zammatteo N, Remacle J, Leclercq G. A low-density DNA microarray for analysis of markers in breast cancer. Int J Biol Markers 2002; 17: 5-23.

[2] Furger KA, Menon RK, Tuck AB, Bramwell VH, Chambers AF. The functional and clinical roles of osteopontin in cancer and metastasis. Curr Mol Med 2001; 1: 621-32.

[3] Weber GF. The metastasis gene osteopontin: a candidate target for cancer therapy. Biochim Biophys Acta 2001; 552: 61-85.

[4] Higashikawa F, Eboshida A, Yokosaki Y. Enhanced biological activity of polymeric osteopontin. FEBS Lett 2007; 581: 2697-1.

[5] Wong KK, Cheng RS, Mok SC. Identification of differentially expressed genes from ovarian cancer cells by MICROMAX cDNA microarray system. Biotechniques 2001; 30: 670-5.

[6] Kim J-H, Skates SJ, Uede T, et al. Osteopontin as a potential diagnostic biomarker for ovarian cancer. JAMA 2002; 287: 1671-9.

[7] Gillespie MT, Thomas RJ, Pu Z-Y, Zhou H, Martin TJ, Findlay DM. Calcitonin receptors, bone sialoprotein and osteopontin are expressed in primary breast cancers. Int J Cancer 1997; 73: 812-5. 
[8] Kadar A, Tõkés A-M, Kulka J, Robert L. Extracellular matrix components in breast carcinomas. Semin Cancer Biol 2002; 12: 243-57.

[9] Tuck AB, Chambers AF, Allan AL. Osteopontin overexpression in breast cancer: knowledge gained and possible implications for clinical management. J Cell Biochem 2007; 102: 859-68.

[10] Rodrigues LR, Teixeira JA, Schmitt F, Paulsson M, LindmarkMänsson $\mathrm{H}$. The role of osteopontin in tumor progression and metastasis in breast cancer. Cancer Epidemiol Biomarkers Prev 2007; 16(6): 1-11.

[11] Brown LF, Berse B, Van de Water L, et al. Expression and distribution of osteopontin in human tissues: widespread association with luminal epithelial surfaces. Mol Biol Cell 1992; 3: 1169-80.

[12] Bramwell VH, Doig GS, Tuck AB, et al. Serial plasma osteopontin levels have prognostic value in metastatic breast cancer. Clin Cancer Res 2006; 12: 3337-43.

[13] Fedarko NS, Jain A, Karadag A, Van Eman MR, Fisher LW. Elevated serum bone sialoprotein and osteopontin in colon, breast, prostate, and lung cancer. Cancer Res 2001; 7: 4060-6.

[14] Bane AL, Pinnaduwage D, Colby S, Bull SB, O’Malley FP, Andrulis IL. Expression profiling of familial breast cancers demonstrates higher expression of EGFR2 in BRCA2-associated tumors. Breast Cancer Res Treat 2008; DOI 10.1007/s10549-008-0087-1

[15] Tuck AB, O’Malley FP, Singhal H, et al. Osteopontin and p53 expression are associated with tumor progression in a case of synchronous, bilateral, invasive mammary carcinomas. Arch Pathol Lab Med 1997; 121: 578-84.

[16] Tuck AB, O'Malley FP, Singhal H, et al. Osteopontin expression in a group of lymph node negative breast cancer patients. Int $\mathrm{J}$ Cancer Predict Oncol 1998; 79: 502-8.

[17] Ue T, Yokozaki H, Kitadai Y, et al. Co-expression of osteopontin and CD44v9 in gastric cancer. Int J Cancer 1998; 79: 127-32.

[18] Senger DR, Ledbetter SR, Claffey KP, Papadopoulos-Sergiou A, Peruzzi CA, Detmar M. Stimulation of endothelial cell migration by vascular permeability factor/vascular endothelial growth factor through cooperative mechanisms involving the alphavbeta 3 integrin, osteopontin, and thrombin. Am J Pathol 1996; 149: 293-05.

[19] Breast Cancer Linkage Consortium. Pathology of familial breast cancer: differences between breast cancers in carriers of BRCA1 or BRCA2 mutations and sporadic cases. Lancet 1997; 349: 1505-9.

[20] Finak G, Bertos N, Pepin F, et al. Stromal gene expression predicts clinical outcome in breast cancer. Nat Med 2008; 14: 518-27.

[21] Bhowmick NA, Moses HL. Tumour-stroma interactions. Curr Opin Genet Dev 2005; 15: 97-01.

[22] Kim JB, Stein R, O'Hare MJ. Tumour-stromal interactions in breast cancer: the role of stroma in tumorigenesis. Tumour Biol 2005; 26 : 173-85.

[23] Tisty TD, Coussens LM. Tumour stroma and regulation of cancer development. Annu Rev Pathol 2006; 1: 119-50.

[24] Breast Cancer Linkage Consortium. Genetic heterogeneity and penetrance analysis of the BRCA1 and BRCA2 genes in breast cancer families. Am J Hum Genet 1998; 62: 676-89.

[25] Chakraborty G, Jain S, Behera R, et al. The multifaceted roles of osteopontin in cell signalling, tumor progression and angiogenesis. Curr Mol Med 2006; 6: 819-30.

[26] Reis-Filho JS, Milanezi F, Paredes J, et al. Novel and classic myoepithelial/stem cell markers in metaplastic carcinomas of the breast. Appl Immunohistochem Mol Morphol 2003; 11: 1-8.

[27] Bellahcène A, Castronovo V. Increased expression of osteonectin and osteopontin, two bone matrix proteins, in human breast cancer. Am J Pathol 1995; 146: 95100.

[28] Kim YW, Park Y-K, Lee J, Ko SW, Yang MH. Expression of osteopontin and osteonectin in breast cancer. J Korean Med Sci 1998; 13: 652-7.

[29] Rudland PS, Platt-Higgins A, El-Tanani M, Rudland SS, Barraclough R. Prognostic significance of the metastasis-associated protein osteopontin in human breast cancer. Cancer Res 2002; 62: 3417-27.

[30] Coppola D, Szabo M, Boulware D, et al. Correlation of osteopontin protein expression and pathological stage across a wide variety of tumor histologies. Clin Cancer Res 2004; 10: 184-90.

[31] Wang G, Platt-Higgins A, Carroll J, et al. Induction of metastasis by $\mathrm{S} 100 \mathrm{P}$ in a rat mammary model and its association with poor survival of breast cancer patients. Cancer Res 2006; 66: 1199-207.

[32] Matos I, Dufloth R, Alvarenga M, Zeferino LC, Schmitt F. p63, cytokeratin 5, and P-cadherin: three molecular markers to distinguish basal phenotype in breast carcinomas. Virchows Arch 2005; 447: 688-94.
[33] Nielsen TO, Hsu FD, Jensen K, et al. Immunohistochemical and clinical characterization of the basal-like subtype of invasive breast carcinoma. Clin Cancer Res 2004; 10: 5367-74.

[34] Sharp JA, Sung V, Slavin J, Thompson EW, Henderson MA. Tumor cells are the source of osteopontin and bone sialoprotein expression in human breast cancer. Lab Invest 1999; 79: 869-77.

[35] Briese J, Schulte H, Bamberger C, Christoph M, Loning T, Bamberger A-M. Expression pattern of osteopontin in endometrial carcinoma: correlation with expression of the adhesion molecule CEACAM1. Int J Gyn Pathol 2006; 25(2): 161-9.

[36] Brown LF, Papadopoulos-Sergiou A, Berse B, et al. Osteopontin expression and distribution in human carcinomas. Am J Pathol 1994; 145: $610-23$.

[37] Tuck AB, Chambers AF. The role of osteopontin in breast cancer: Clinical and experimental studies. J Mammary Gland Biol Neoplasia 2001; 6: 419-29.

[38] Wai PY, Kuo PC. The role of osteopontin in tumor metastasis. J Surg Res 2004; 121: 228-41.

[39] Rudland PS, Platt-Higgins A, Renshaw C, et al. Prognostic significance of the metastasis-inducing protein S100A4 (p9Ka) in human breast cancer. Cancer Res 2000; 60: 1595-602.

[40] Ribeiro-Silva A, Oliveira da Costa JP. Osteopontin expression according to molecular profle of invasive breast cancer: a clinicopathological and immunohistochemical study. Int J Biol Markers 2008; 23(3): 154-60.

[41] Sheridan C, Kishimoto H, Fuchs RK, et al. CD44+/CD24- breast cancer cells exhibit enhanced invasive properties: an early step necessary for metastasis. Breast Cancer Res 2006; 8: R59.

[42] Slamon DJ, Clark GM, Wong GG, Levin WJ, Ullirich A, McGuire WL. Human breast cancer: correlation of relapse and survival with amplification of the HER-2/neu oncogene. Science 1987; 235: 17787.

[43] Herrera-Gayol A, Jothy S. Adhesion proteins in the biology of breast cancer: contribution of CD44. Exp Mol Pathol 1999; 66: 149-56.

[44] Allan AL, George R, Vantyghem SA, et al. Role of the integrinbinding protein osteopontin in lymphatic metastasis of breast cancer. Am J Pathol 2006; 169: 233-46.

[45] Sodek J, Ganss B, McKee MD. Osteopontin. Crit Rev Oral Biol Med 2000; 11: 279-03.

[46] Sung V, Gilles C, Murray A, et al. The LCC15-MB human breast cancer cell line expresses osteopontin and exhibits an invasive and metastatic phenotype. Exp Cell Res 1998; 241: 273-84.

[47] Thomas PA, Kirschmann DA, Cerhan JR, et al. Association between keratin and vimentin expression, malignant phenotype and survival in postmenopausal breast cancer patients. Clin Cancer Res 1999; 5: 2698-703.

[48] Cheng S-L, Shin CS, Towler DA, Civitelli R. A dominant negative cadherin inhibits osteoblast differentiation. J Bone Min Res 2000; 15: 2362-70.

[49] Paredes J, Stove C, Stove V, et al. P-Cadherin is up-regulated by the antiestrogen ICI 182, 780 and promotes invasion of human breast cancer cells. Cancer Res 2004; 64: 8309-17.

[50] Paredes J, Albergaria A, Oliveira JT, Jerónimo C, Milanezi F, Schmitt F. P-Cadherin overexpression is an indicator of clinical outcome in invasive breast carcinomas and is associated with $\mathrm{CDH} 3$ promoter hypomethylation. Clin Cancer Res 2005; 11: 5869-77.

[51] Tuck AB, Elliott BE, Hota C, Tremblay E, Chambers AF. Osteopontin-induced, integrin-dependent migration of human mammary epithelial cells involves activation of the hepatocyte growth factor receptor (Met). J Cell Biochem 2000; 78: 465-75.

[52] Tuck AB, Hota C, Wilson SM, Chambers AF. Osteopontin-induced migration of human mammary epithelial cells involves activation of EGF receptor and multiple signal transduction pathways. Oncogene 2003; 22: 1198-205.

[53] Das R, Mahabeleshwar GH, Kundu GC. Osteopontin induces AP-1mediated secretion of urokinase-type plasminogen activator through c-Src-dependent epidermal growth factor receptor transactivation in breast cancer cells. J Biol Chem 2004; 279: 11051-64.

[54] El-Tanani MK, Campbell FC, Kurisetty V, Jin D, McCann M, Rudland PS. The regulation and role of osteopontin in malignant transformation and cancer. Cytokine Growth Factor Rev 2006; 17: 46374.

[55] Burrows FJ, Derbyshire EJ, Tazzari PL, et al. Up-regulation of endoglin on vascular endothelial cells in human solid tumors: implications for diagnosis and therapy. Clin Cancer Res 1995; 1: 1623-34. 
[56] Balza E, Castellani P, Zijlstra A, Neri D, Zardi L, Siri A. Lack of specificity of endoglin expression for tumor blood vessels. Int J Cancer 2001; 94: 579-85.
[57] Tiniakos DG, Yu H, Liapis H. Osteopontin expression in ovarian carcinomas and tumors of low malignant potential (LMP). Hum Pathol 1998; 29: 1250-4.

(C) Rodrigues et al.; Licensee Bentham Open .

This is an open access article licensed under the terms of the Creative Commons Attribution Non-Commercial License (http://creativecommons.org/licenses/by-nc/ $3.0 /$ ) which permits unrestricted, non-commercial use, distribution and reproduction in any medium, provided the work is properly cited. 